\title{
Opinião de adolescentes com deficiência visual e de profissionais em relação à comunicação do sujeito surdocego.
}

\begin{abstract}
Resumo
Fernanda O. Narita (IC), Maria Elisabete R. F. Gasparetto (PQ).

Esta pesquisa teve como objetivo conhecer, sob o olhar fonoaudiológico, a comunicação entre uma adolescente surdocega, os adolescentes com deficiência visual e os profissionais de reabilitação. Foi realizada por meio de um estudo de caso e a coleta de dados se deu por meio de entrevistas semiestruturadas. Para a comunicação com a adolescente, os profissionais e os adolescentes com deficiência visual informaram a prevalência da comunicação verbal, juntamente com a elevação da intensidade da voz, a proximidade, o toque associado à fala e a posição no espaço. Verificou-se que além da comunicação verbal entre os participantes, havia também entre eles, a comunicação não verbal, surgindo como estratégia resolutiva e facilmente aplicável na intervenção fonoaudiológica.
\end{abstract}

Palavras Chave: Comunicação, Fonoaudiologia, Transtornos da Surdocegueira.

\section{Introdução}

Surdocegueira é uma deficiência singul ar que apresenta perdas auditivas e visuais concomitantemente em diferentes graus, levando a pessoa surdocega a desenvolver diferentes formas de comunicação para entender e interagir com as pessoas e com o meio ambiente ${ }^{1}$. Os surdocegos podem ter dificuldades em estabelecer e manter relacionamentos interpessoais ${ }^{2}$. A reabilitação grupal propicia que essas dificuldades sejam reduzidas ou eliminadas. Considerando tais informações, esta pesquisa teve como objetivo geral, conhecer sob o olhar fonoaudiológico, a comunicação entre uma adolescente surdocega, os adolescentes com deficiência visual e os profissionais de reabilitação. Foi realizado um estudo de caso de cunho qualitativo ${ }^{3}$ e a coleta de dados se deu por meio de entrevistas semiestruturadas.

\section{Resultados e Discussão}

A adolescente relatou que utilizava a comunicação verbal com os adolescentes e com os profissionais da reabilitação. Para a comunicação com a adolescente, os profissionais e os adolescentes com deficiência visual informaram a prevalência da comunicação verbal, juntamente com a elevação da intensidade da voz, a proximidade, o toque associado à fala e a posição no espaço. Para melhorar a comunicação verbal e não verbal, a adolescente declarou utilizar recursos não ópticos (ampliação, contraste, iluminação), recursos ópticos (lupas e telescópico) e a informática. A adolescente utilizou prótese auditiva, mas, foi abandonada porque ficou sem bateria. A mãe relatou que a manutenção da prótese era muito dispendiosa e por isso, as baterias não eram repostas.
Posteriormente, a prótese foi submetida à manutenção, mas a adolescente fez uso esporádico e sempre com os cabelos soltos para que a prótese não fosse identificada. No entanto, os adolescentes e os profissionais declararam perceber a mudança de comportamento da adolescente, quando utilizava a prótese apresentando maior interação e participação nas atividades grupais confirmando a afirmação de Almeida e lório (2003) de que a prótese auditiva é a pedra fundamental no processo de reabilitação.

\section{Conclusões}

Verificou-se que apesar da prevalência da comunicação verbal entre a adolescente surdocega, os adolescentes com deficiência visual $e$ os profissionais que atuavam no programa de reabilitação, havia também entre eles a comunicação não verbal, surgindo como estratégia resolutiva e facilmente aplicável na intervenção fonoaudiológica.

\section{Agradecimentos}

Aos participantes, ao orientador e ao PIBIC.

1. Cormedi, M. A. Referências de currículo na elaboração de programas educacionais individualizados para surdocegos congênitos e múltiplos deficien tes. Dissertação (Mestrado) Programa em Distúrbios de Desenvolvimento Universidade Presbiteriana Mackenzie, 2005.

2. Etheridge, D. The Education of Dual Sensory Impaired Children. London: David Fulton Publishers Ltd, 1995, p. 9-18.

3. Gil AC. Como elaborar Projetos de Pesquisa. 5a ed. São Paulo: Atlas, 2010.

4. Almeida K. e Iorio M.C.M. Próteses auditivas: fundamentos teóricos e aplicações clínicas. 2. ed. São Paulo: Lovise, 2003. 